\title{
EXTREME RANKED REPETITIVE SAMPLING CONTROL CHARTS
}

\author{
Amjad D. Al-Nasser ${ }^{1 *}$, Enrico Ciavolino ${ }^{2}$ and Amer Al-Omari ${ }^{3}$
}

Received May 16, 2019 / Accepted December 3, 2019

\begin{abstract}
In this paper, we proposed a new ranked data control chart using repetitive sampling criterion to increase the performance of detecting any shift in mean process. For the comparisons target, the average run length (ARL) of the proposed control chart based on repetitive extreme ranked set sampling computed using exact and estimated parameters. The results showed that the ARL affected negatively by the parameter estimation. Moreover, the performances of the proposed control chart is evaluated and compared with similar control chart that obtained by using different sampling schemes such as the simple random sampling, ranked set sampling, extreme ranked set sampling and repetitive ranked set sampling.. The results showed that the ranked data based control chart outperform the classical control chart in terms of the ARL.
\end{abstract}

Keywords: extreme ranked set sampling, ranked set sampling, repetitive sampling, Shewhart control chart, average run length.

\section{INTRODUCTION}

Control charts are statistical techniques that have been widely used in monitoring product quality during the manufacturing process. There are several control charts, however, the most used is the $\mathrm{X}$ bar control chart that proposed by Shewhart (1924). More details about the usual control chart can be found in Montgomery, 2009; Claro et al., 2008; Costa and Machado, 2007; Al-Nasser and Gogah, 2017; Gogah and Al-Nasser, 2018; Al-Omari, 2015; Al-Omari et al, 2016; Huang et al, 2017; Yaqub et al, 2016; and Haridy et al, 2016.

The performances of the Shewhart control charts, evaluated by the average run length (ARL) criterion, where the precision of the ARL depends on the sampling scheme used: single sampling, double sampling, sequential sampling, or repetitive sampling (RS). It is well known that double sampling is more accurate and more efficient than the single sampling scheme, however, RS

\footnotetext{
*Corresponding author

${ }^{1}$ Department of Statistics, Science Faculty, Yarmouk University, Irbid, Jordan - E-mail: amjadyu@yahoo.com https://orcid.org/0000-0001-7515-2357

2 Department of History, Society and Human Studies, University of Salento, Lecce, Italy - E-mail: enrico.ciavolino@unisalento.it - https://orcid.org/0000-0003-3955-4310

3 Department of Mathematics, Faculty of Science, Al al-Bayt University, Mafraq, Jordan - E-mail: alomari_amer@yahoo.com - https://orcid.org/0000-0002-6901-8263
} 
outperform the double sampling scheme, while the sequential sampling robustify all sampling schemes (Rodrigues et al, 2011; Shu et al, 2014; He et al., 2002, Baklizi et al., 2005).

In this article, we are interesting in using RS scheme. The main idea of the RS scheme originally proposed by Sherman (1965), who suggested using this sampling scheme for developing attributes acceptance-sampling plans. Then after, Balamurali and Jun (2006), used RS scheme to develop more efficient acceptance sampling plan under normality assumption and for two cases, the first one by assuming the variance is known and the other one by assuming the variance is unknown.

The application of RS in developing control charts was discussed by Ahmad et al. (2014), they showed that the $\mathrm{t}$ chart shows a better performance by using a RS scheme. Also, Aslam et al, (2014), they suggested of using the RS scheme in developing $\mathrm{x}$ bar control chart for the process capability. For more details on RS scheme in control chart context see Al-Nasser and Aslam, 2019; Aslam et al, 2017; Nezhad and Saredorahi, 2018; and Yan et al, 2017.

The basic mechanism of RS consists in drawing a simple random sample (SRS) repetitively till successfully a sample met the criterion or the specifications under study. In the literature, it is shown that the SRS has some weaknesses in estimating the location parameters comparing to the random samples based on the ranks or the so called ranked set sampling (RSS) (Al-Nasser and Al-Rawwash, 2007).

McIntyre (1952), is the first who introduced the RSS scheme without any theoretical background, in order to estimate the mean pasture and forage yields. Later, Takahasi and Wakimoto (1968), developed the first statistical theory of the RSS scheme, and showed that the RSS mean is an unbiased estimator of the population mean, and it is more efficient than the sample mean obtained from simple random sampling (SRS) of the same size. For more details on RSS schemes refer to Ozturk, 2016; Frey, 2016; Haq et al., 2014; Haq et al., 2016, Zamanzade and Al-Omari, 2016; Al-Nasser, 2007; Al-Nasser et al., 2013; Al-Nasser and Al-Omari, 2018 and Al-Nasser and AlOmari, 2015. In this article we are interested in using extreme RSS (ERSS) within the RS scheme to develop an efficient Shewhart control chart.

The rest of the paper organized as follows: ERSS discussed in Section 2. The proposed repetitive ranked control chart discussed in Section.3. Comparative studies using Monte Carlo experiments are given in Section 4. The last section contains concluding remarks.

\section{EXTREME RANKED SET SAMPLING}

In order to plan an ERSS design (Al-Nasser and Mustafa, 2009), $n$ random samples each of size $n$ sampling units should be drawn. Then only one of the extreme sampling units (minimum or maximum) will be measured from each sample, sequentially. The ERSS scheme can be described with the following steps:

Step.1 Select $n$ random samples each of size $n$ units 
Step.2 Rank the units within each sample with respect to a variable of interest through/by means of visual inspection or any other cost-free method.

Step.3 For each of the first $\left[\frac{n}{2}\right]$ ranked samples; select the "minimum value" unit with rank 1 for actual measurement.

Step.4 For each of the last $\left[\frac{n}{2}\right]$ ranked samples, select the "maximum value" unit with rank $n$ for actual measurement.

Step.5 To complete the cycle, i.e., if $n$ is odd; the unit with rank $\left[\frac{n+1}{2}\right]$ is selected for actual measurement.

Step.6 The cycle may be repeated $m$ times to obtain the desired sample size $n * m$.

Then the sample mean can be defined as:

$$
\hat{x}_{\text {ERSS }}=\left\{\begin{array}{c}
\frac{1}{m n} \sum_{j=1}^{m}\left(\sum_{i=1}^{\frac{n}{2}} X_{[1: n] i, j}+\sum_{i=\frac{n}{2}+1}^{n} X_{[n: n] i, j}\right) ; n \text { is even } \\
\frac{1}{m n} \sum_{j=1}^{m}\left(\sum_{i=1}^{\frac{n}{2}-1} X_{[1: n] i, j}+\sum_{i=\frac{n}{2}}^{n-1} X_{[n: n] i, j}+X_{\left[\frac{n+1}{2}: n\right] i, j}\right) ; n \text { is odd }
\end{array}\right.
$$

where $X_{[k: n] i, j}$ is the $k^{\text {th }}$ order statistics of the $i^{\text {th }}$ random sample of size $n$ in the $j^{\text {th }}$ cycle.

The expected value of the sample mean from ERSS is equal to:

$$
\mu_{\text {ERSS }}=E\left(\dot{x}_{E R S S}\right)=\left\{\begin{array}{c}
\frac{1}{2}\left(\mu_{(1)}+\mu_{(n)}\right) ; n \text { is even } \\
\frac{n-1}{2 n}\left(\mu_{(1)}+\mu_{(n)}\right)+\frac{1}{n} \mu_{\left(\frac{n+1}{2}\right)} ; n \text { is odd }
\end{array}\right.
$$

where $\mu_{(i)}$ is the expected value (mean) of the $i^{\text {th }}$ order statistics from a sample of size $n$. Then the associated variance of $\dot{x}_{E R S S}$ is $\sigma_{E R S S}^{2}$ and equal to

$$
\sigma_{\text {ERSS }}^{2}=\left\{\begin{array}{c}
\frac{1}{2 n}\left(\sigma_{(1)}^{2}+\sigma_{(n)}^{2}\right) ; n \text { is even } \\
\frac{(n-1)}{2 n^{2}}\left(\sigma_{(1)}^{2}+\sigma_{(n)}^{2}\right)+\frac{1}{n^{2}} \sigma_{\left(\frac{n+1}{2}\right)}^{2} ; n \text { is odd }
\end{array}\right.
$$

where $\sigma_{(i)}^{2}$ is the variance of the $i^{t h}$ order statistics from a sample of size $n$. Consequently, we may present the Shewhart control limits in the following manner:

$$
\begin{aligned}
& \mathrm{LCL}=\mu-3 \sigma_{\bar{X}_{E R S S}} \\
& \mathrm{CL}=\mu \\
& \mathrm{UCL}=\mu+3 \sigma_{\bar{X} E R S S}
\end{aligned}
$$

Comparison and summarization of the control charts presented in this article conducted by using different quality control limits that depends on the different sampling scheme. The ARL used as an evaluation's criteria of the control chart performance. The ARL is the most commonly used statistics in the literature assuming that the process is under control with actual process mean $\mu_{0}$ and actual process variance $\sigma_{0}^{2}$.The process may go out of control if the mean $\mu_{0}$ shift of the amount $\left(\frac{\delta \sigma_{0}}{\sqrt{n}}\right)$, where $\delta$ is constant with nonnegative values chosen to cover wide range of the shift in mean $\mu$. 
Moreover, if $\delta=0$, then the process is in a state of control. Otherwise, it starts to get out of control as $\delta$ gets larger. Therefore, if $\delta=0$, then any point falling outside the upper or lower control limit is considered as a false alarm (Montgomery, 2009).

\section{PROPOSED CONTROL CHART}

We propose a Shewhart ranked control chart using repetitive sampling within an Extreme ranked repetitive sampling scheme. Accordingly, there are two types of limits, outer (LCL1 and UCL1) and inner (LCL2 and UCL2) control chart limits. Then, the extreme ranked repetitive control chart for the sample mean consists of the following steps:

Step 1: Draw a RSS of size $n$.

Step 2: Calculate the sample mean $\bar{X}_{\text {ERSS }}$

Step 3: Declare the following decision about the entire process:

$$
\left\{\begin{array}{c}
\text { Out of Control, if } ;>U C L_{1} \vee<L C L_{1} \\
\in \text { Control if } ; L C L_{2}<U C L_{2} \\
\text { Otherwise; } \Re \text { Sample }
\end{array}\right.
$$

Where the outer control chart limits are given by:

$$
\begin{aligned}
& U C L_{1}=\mu_{\text {erss } 0}+k_{1} \\
& L C L_{1}=\mu_{\text {erss } 0}-k_{1}
\end{aligned}
$$

Similarly, the inner control chart limits are given by:

$$
\begin{aligned}
& U C L_{2}=\mu_{\text {erss } 0}+k_{2} \\
& L C L_{2}=\mu_{\text {erss } 0}-k_{2}
\end{aligned}
$$

Then the probability that the process is declared as in control is:

$$
P_{\in_{R S S}}=\frac{P\left(L C L_{2}<U C L_{2} \vee \mu_{\text {erss }}=\mu_{\text {erss } 0}\right)}{1-P_{\text {rep }}}
$$

Where the probability that repetitive sampling is needed can be obtained by:

$$
P_{\text {rep }} \text { ERSS }=P\left(U C L_{2}<U C L_{1}\right)+P\left(L C L_{1}<L C L_{2}\right)
$$

Hence, the in-control average run length (ARL) is given by:

$$
A R L_{\text {Ers } O}=\frac{1}{1-P_{\text {rep }_{\text {ERSS }}}}
$$

Suppose now that the process mean has shifted from $\mu_{r s s 0}$ to $\mu_{r s s 0}+\delta \sigma$. Then, the probability that the process is declared as out of control is obtained by:

$$
P_{\epsilon_{\text {erss }}}^{*}=\frac{P\left(L C L_{2}<U C L_{2} \vee \mu_{\text {erss }}=\mu_{\text {erss } 0}+\delta \sigma_{\text {erss }}\right)}{1-P_{\text {rep }}^{*}}
$$


Similarly, the ARL for out of control process will be

$$
A R L_{1_{\text {erss }}}=\frac{1}{1-P_{\text {rep erss }}^{*}}
$$

In general, the steps of ranked repetitive sampling control chart can be summarized as follows:

Step.1 Using the assumption that the control chart is under control, Specify the value of $A R L_{0}$

Step.2 Seek the values of the control charts multipliers $k 1$ and $k 2(k 1>k 2)$ by minimizing ASN0 given that ARLO is more than or equals the target. Noting that $A S N 0=\frac{n}{1-P_{\text {rep }} E_{E S S}}$, then the optimization problem will be:

\section{Minimize ASNO}

$$
\text { Subject to (1) } \mathrm{ARL}_{0} \geq \mathrm{r}_{0}
$$

(2) $\mathrm{k} 1>\mathrm{k} 2$

Step.3 Find the value of ARL assuming that the process is out of control.

\subsection{Performance of the control chart}

Monte Carlo simulation experiments were used to study the performance of the extreme ranked control charts under the following assumptions:

Step.1 Setting up the control chart components: Sample mean and Sample variance

- Generate 1000000 ERSS each of size $m=3,4,5$, and 6 from the standard normal distribution

- Note that the exact variance under normal distribution using ERSS can be computed:

\begin{tabular}{|c|c|}
\hline Sample size & Variance based on ERSS \\
\hline 3 & 0.174178 \\
\hline 4 & 0.122929 \\
\hline 5 & 0.0830788 \\
\hline 6 & 0.0693212 \\
\hline
\end{tabular}

- Compute the grand mean from the 1000000 subgroups.

Step.2 Setting up the unknown control limits multipliers

- Chose an initial values of the $\mathrm{ARL}_{0 \_ \text {erss }}=100$ and 150 .

- Select an initial values of $k 1$ and $k 2$. 
- Use the generating samples from step.1 and an optimization problem in order to minimize the ASN0_rss and find the optimal values of $k 1$ and $k 2$.

- Compute the control chart limits (LCL1,UCL1) and (LCL2, UCL2)

Step. 3 Compute the $\mathrm{ARL}_{0}$ and $\mathrm{ARL}_{1}$

- Follow the procedure of the proposed control chart and check if the process is declared

- as In-control, out-of-control or re-sampling.

- compute the number the in-control run length say $(\mathrm{R})$. Then the $\mathrm{ARL}_{0 \_r s s}=\mathrm{R} / 1000000$

- Compute $\mathrm{ARL}_{1 \_ \text {_erss }}$ as $\delta=0.1,0.2, \ldots, 3.4$

The results of this Monte Carlo experiment are given in Table 1 and Table 2. The simulation results indicate that for the same values of $n, k 1$ and $k 2$, we note decreasing trend in average run length as $\delta$ changes from 0.0 to 3.4. The values of k1 are around 3.0, however, k2, has different values for different sample size in order to satisfy the target ARL. Moreover, the ASN decreases as $\delta$ increases. In addition, for different values of the ARL, we may have the same control chart limits, but that will affect on the ASN.

Noting that, in practice the process mean and the variance are unknown, then one can use unbiased estimators for the process mean using (1) and unbiased point estimator for the process variance $\widehat{\sigma}_{E R S S}^{2}$. Then the estimated control limits (inner and outer limits) will be computed based on the observed data as:

$$
\begin{aligned}
& \widehat{U C L_{1}}=\widehat{\mu}_{\text {erss } 0}+k_{1} \widehat{\sigma}_{\dot{X}_{E R S S}} \\
& \widehat{U C L_{2}}=\widehat{\mu}_{\text {erss } 0}+k_{2} \widehat{\sigma}_{\dot{X}_{E R S S}} \\
& \widehat{L C L_{2}}=\widehat{\mu}_{\text {erss }}-k_{2} \widehat{\sigma}_{\dot{X}_{E R S S}} \\
& \widehat{L C L_{1}}=\widehat{\mu}_{\text {erss }}-k_{1} \widehat{\sigma}_{\dot{X}_{E R S S}}
\end{aligned}
$$

The parameter estimation effect on the performance of the control chart (Chakraborti, 2000; Epprecht et al., 2015; Jardim, et al., 2019; Saleh, et al., 2015). We conduct a Monte Carlo experiment to study the effect of the estimated parameters under the following assumptions:

Step.1 Generate 1000000 ERSS each of size $m=3,4,5$, and 6 from the standard normal distribution

- Calculate the sample mean and the sample variance within each subgroup.

- Compute the grand mean from the 1000000 subgroups. 
Table $1-$ ASN and ARL when $r_{0}$ is 100 .

\begin{tabular}{|c|c|c|c|c|c|c|c|c|}
\hline & \multicolumn{2}{|c|}{$\begin{array}{c}\mathrm{N}=3 \\
\mathrm{~K} 1=2.99 ; \mathrm{K} 2=1.08\end{array}$} & \multicolumn{2}{|c|}{$\begin{array}{c}\mathrm{N}=4 \\
\mathrm{~K} 1=3.00 ; \mathrm{K} 2=0.98\end{array}$} & \multicolumn{2}{|c|}{$\begin{array}{c}\mathrm{N}=5 \\
\mathrm{~K} 1=3.00 ; \mathrm{K} 2=0.96\end{array}$} & \multicolumn{2}{|c|}{$\begin{array}{c}\mathrm{N}=6 \\
\mathrm{~K} 1=3.01 ; \mathrm{K} 2=0.94\end{array}$} \\
\hline & ASN & ARL & ASN & ARL & ASN & ARL & ASN & ARL \\
\hline 0 & 502 & 102.04 & 450 & 102.04 & 1005 & 100.00 & 707 & 101.11 \\
\hline 0.1 & 405 & 91.74 & 338 & 56.18 & 776 & 75.19 & 493 & 75.19 \\
\hline 0.2 & 289 & 52.63 & 258 & 43.48 & 566 & 42.37 & 363 & 60.24 \\
\hline 0.3 & 224 & 47.17 & 157 & 36.36 & 409 & 30.58 & 270 & 37.74 \\
\hline 0.4 & 159 & 34.36 & 126 & 22.78 & 321 & 24.45 & 192 & 29.50 \\
\hline 0.5 & 119 & 24.21 & 70 & 17.57 & 215 & 17.79 & 118 & 24.33 \\
\hline 0.6 & 70 & 16.58 & 57 & 12.58 & 176 & 13.11 & 105 & 15.72 \\
\hline 0.7 & 58 & 13.68 & 42 & 10.03 & 112 & 10.10 & 63 & 11.71 \\
\hline 0.8 & 40 & 9.91 & 27 & 7.94 & 59 & 7.94 & 34 & 8.83 \\
\hline 0.9 & 33 & 8.47 & 18 & 6.27 & 50 & 6.13 & 26 & 6.60 \\
\hline 1 & 18 & 6.80 & 14 & 5.04 & 39 & 4.96 & 13 & 5.38 \\
\hline 1.1 & 16 & 5.58 & 8 & 4.19 & 25 & 4.04 & 9 & 4.24 \\
\hline 1.2 & 13 & 4.56 & 9 & 3.51 & 20 & 3.33 & 10 & 3.56 \\
\hline 1.3 & 8 & 3.91 & 5 & 2.96 & 15 & 2.89 & 11 & 2.92 \\
\hline 1.4 & 8 & 3.33 & 5 & 2.58 & 11 & 2.44 & 6 & 2.56 \\
\hline 1.5 & 5 & 2.86 & 4 & 2.27 & 10 & 2.14 & 6 & 2.22 \\
\hline 1.6 & 3 & 2.48 & 4 & 2.00 & 5 & 1.88 & 6 & 1.94 \\
\hline 1.7 & 3 & 2.19 & 4 & 1.79 & 6 & 1.69 & 6 & 1.76 \\
\hline 1.8 & 3 & 1.99 & 4 & 1.63 & 5 & 1.55 & 6 & 1.55 \\
\hline 1.9 & 5 & 1.78 & 5 & 1.52 & 5 & 1.43 & 6 & 1.43 \\
\hline 2 & 3 & 1.62 & 4 & 1.39 & 5 & 1.33 & 6 & 1.35 \\
\hline 2.1 & 3 & 1.47 & 4 & 1.30 & 5 & 1.27 & 6 & 1.26 \\
\hline 2.2 & 3 & 1.40 & 4 & 1.25 & 5 & 1.19 & 6 & 1.20 \\
\hline 2.3 & 3 & 1.31 & 4 & 1.19 & 5 & 1.16 & 6 & 1.15 \\
\hline 2.4 & 3 & 1.24 & 4 & 1.15 & 5 & 1.12 & 6 & 1.11 \\
\hline 2.5 & 3 & 1.20 & 4 & 1.11 & 5 & 1.09 & 6 & 1.08 \\
\hline 2.6 & 3 & 1.15 & 4 & 1.08 & 5 & 1.07 & 6 & 1.06 \\
\hline 2.7 & 3 & 1.12 & 4 & 1.06 & 5 & 1.04 & 6 & 1.05 \\
\hline 2.8 & 3 & 1.10 & 4 & 1.05 & 5 & 1.03 & 6 & 1.03 \\
\hline 2.9 & 3 & 1.08 & 4 & 1.04 & 5 & 1.03 & 6 & 1.02 \\
\hline 3 & 3 & 1.06 & 4 & 1.02 & 5 & 1.02 & 6 & 1.01 \\
\hline 3.1 & 3 & 1.04 & 4 & 1.02 & 5 & 1.01 & 6 & 1.01 \\
\hline 3.2 & 3 & 1.03 & 4 & 1.01 & 5 & 1.01 & 6 & 1.01 \\
\hline 3.3 & 3 & 1.02 & 4 & 1.01 & 5 & 1.01 & 6 & 1.00 \\
\hline 3.4 & 3 & 1.02 & 4 & 1.01 & 5 & 1.00 & 6 & 1.00 \\
\hline
\end{tabular}


Table 2 - ASN and ARL when $r_{0}$ is 150.

\begin{tabular}{|c|c|c|c|c|c|c|c|c|}
\hline & \multicolumn{2}{|c|}{$\begin{array}{c}\mathrm{N}=3 \\
\mathrm{~K} 1=3.01 ; \mathrm{K} 2=1.01\end{array}$} & \multicolumn{2}{|c|}{$\begin{array}{c}\mathrm{N}=4 \\
\mathrm{~K} 1=3.01 ; \mathrm{K} 2=0.99\end{array}$} & \multicolumn{2}{|c|}{$\begin{array}{c}\mathrm{N}=5 \\
\mathrm{~K} 1=3.00 ; \mathrm{K} 2=0.96\end{array}$} & \multicolumn{2}{|c|}{$\begin{array}{c}\mathrm{N}=6 \\
\mathrm{~K} 1=3.01 ; \mathrm{K} 2=0.93\end{array}$} \\
\hline & ASN & ARL & ASN & ARL & ASN & ARL & ASN & ARL \\
\hline 0 & 1048 & 151.25 & 898 & 153.85 & 1446 & 153.73 & 1035 & 156.25 \\
\hline 0.1 & 798 & 140.85 & 645 & 116.28 & 1069 & 104.17 & 789 & 125.00 \\
\hline 0.2 & 564 & 99.01 & 451 & 81.30 & 808 & 74.63 & 567 & 106.38 \\
\hline 0.3 & 470 & 86.21 & 309 & 56.82 & 594 & 52.91 & 407 & 54.05 \\
\hline 0.4 & 347 & 54.64 & 275 & 39.37 & 448 & 38.46 & 298 & 42.55 \\
\hline 0.5 & 272 & 40.49 & 164 & 31.85 & 340 & 29.41 & 215 & 29.07 \\
\hline 0.6 & 192 & 32.05 & 128 & 24.27 & 229 & 20.37 & 139 & 22.73 \\
\hline 0.7 & 135 & 22.22 & 76 & 16.75 & 167 & 15.15 & 99 & 15.38 \\
\hline 0.8 & 105 & 16.75 & 62 & 13.53 & 113 & 11.61 & 52 & 11.86 \\
\hline 0.9 & 77 & 13.42 & 38 & 9.99 & 74 & 9.08 & 47 & 10.00 \\
\hline 1 & 51 & 10.04 & 37 & 8.15 & 56 & 6.95 & 33 & 6.95 \\
\hline 1.1 & 32 & 8.35 & 26 & 6.61 & 47 & 5.90 & 22 & 5.95 \\
\hline 1.2 & 30 & 6.64 & 16 & 5.22 & 25 & 4.64 & 13 & 4.60 \\
\hline 1.3 & 13 & 5.44 & 8 & 4.32 & 19 & 3.82 & 11 & 3.64 \\
\hline 1.4 & 10 & 4.52 & 9 & 3.52 & 12 & 3.23 & 8 & 3.17 \\
\hline 1.5 & 12 & 3.80 & 6 & 3.03 & 6 & 2.62 & 7 & 2.60 \\
\hline 1.6 & 7 & 3.25 & 8 & 2.61 & 6 & 2.32 & 6 & 2.26 \\
\hline 1.7 & 3 & 2.75 & 4 & 2.31 & 5 & 2.02 & 6 & 2.01 \\
\hline 1.8 & 8 & 2.41 & 4 & 2.02 & 6 & 1.83 & 7 & 1.79 \\
\hline 1.9 & 3 & 2.15 & 4 & 1.83 & 7 & 1.64 & 6 & 1.58 \\
\hline 2 & 3 & 1.94 & 4 & 1.65 & 5 & 1.50 & 6 & 1.47 \\
\hline 2.1 & 4 & 1.75 & 4 & 1.50 & 5 & 1.40 & 6 & 1.36 \\
\hline 2.2 & 5 & 1.59 & 4 & 1.40 & 5 & 1.29 & 6 & 1.26 \\
\hline 2.3 & 4 & 1.49 & 4 & 1.31 & 5 & 1.24 & 6 & 1.22 \\
\hline 2.4 & 3 & 1.39 & 4 & 1.25 & 5 & 1.18 & 6 & 1.16 \\
\hline 2.5 & 3 & 1.30 & 4 & 1.19 & 5 & 1.14 & 6 & 1.11 \\
\hline 2.6 & 3 & 1.26 & 4 & 1.16 & 5 & 1.11 & 6 & 1.08 \\
\hline 2.7 & 3 & 1.20 & 4 & 1.12 & 5 & 1.08 & 6 & 1.07 \\
\hline 2.8 & 3 & 1.16 & 4 & 1.09 & 5 & 1.06 & 6 & 1.04 \\
\hline 2.9 & 3 & 1.12 & 4 & 1.07 & 5 & 1.04 & 6 & 1.03 \\
\hline 3 & 3 & 1.10 & 4 & 1.05 & 5 & 1.03 & 6 & 1.02 \\
\hline 3.1 & 3 & 1.07 & 4 & 1.03 & 5 & 1.02 & 6 & 1.01 \\
\hline 3.2 & 3 & 1.05 & 4 & 1.03 & 5 & 1.01 & 6 & 1.01 \\
\hline 3.3 & 3 & 1.04 & 4 & 1.02 & 5 & 1.01 & 6 & 1.01 \\
\hline 3.4 & 3 & 1.03 & 4 & 1.01 & 5 & 1.01 & 6 & 1.00 \\
\hline
\end{tabular}


Step.2 Select an initial values of $k 1=3$ and $k 2=1.5$.

- Compute the control chart limits (LCL1,UCL1) and (LCL2, UCL2)

Step.3 Compute the $\mathrm{ARL}_{0}$ and $\mathrm{ARL}_{1}$

- Follow the procedure of the proposed control chart and check if the process is declared

- as In-control, out-of-control or re-sampling.

- compute the number the in-control run length say $(\mathrm{R})$. Then the $\mathrm{ARL}_{0_{\text {_rss }}=\mathrm{R} / 1000000}$

- Compute $\mathrm{ARL}_{1 \_ \text {erss }}$ as $\delta=0.1,0.2, \ldots, 3.4$

In this experiment, the ARL of the control charts based on the exact parameters and the estimated parameters are computed. The results are given in Figure 1 indicated that the control charts the affected negatively by parameter estimation and the ARL when the chart is under control or out of control are larger than the ARL values that used the exact parameter values for all set sizes.

\section{COMPARATIVE STUDY}

In this section, Monte Carlo experiments using several sampling approaches of the quality control scheme are considered under the normality assumption and perfect ranking mechanism. The ARL is computed for the classical (based on SRS and RSS) and the proposed (Rep-RSS and Rep-ERSS) Shewhart control charts. It is worth to note that under the SRS procedure, the ARL of the $\bar{X}$ chart will be 370 . Accordingly, when the process under control the ARL are assumed to have the same value " 370 " then another experiment is conducted to find the optimal multipliers values under all sampling approaches. Moreover, when the process is out of control the ARL is computed for shifted value $\delta=0.0,0.1,0.2,0.3,0.4,0.5,1.0,1.8,2.6$ and 3.4. The results of the Monte Carlo experiments are given in Tables 3-6. The RS of the novel RSS is obtained from Al-Nasser (2017). The general results in the tables indicated that:

- When the control chart is in control, the RS with RSS are more accurate

- Regardless the sample size the ARL is the same for RS Ranked samples schemes.

- As the chart start to be in out of control stage, the ARL is decreases as $\delta$ increases.

- The $\mathrm{ARL}_{1}$ using Rep-ERSS is less than the $\mathrm{ARL}_{1}$ based on all sampling schemes used in this comparative study.

It could be noted that, when the sub sample size is 3 within the repetitive sampling schemes and for fixed value of the $\mathrm{ARL}_{0}$ (equal to 370), the $\mathrm{ARL}_{1}$ values depends on the inner and outer coefficients limits $\mathrm{k} 1$ and $\mathrm{k} 2$. To understand this we may compute the ratio between these two 

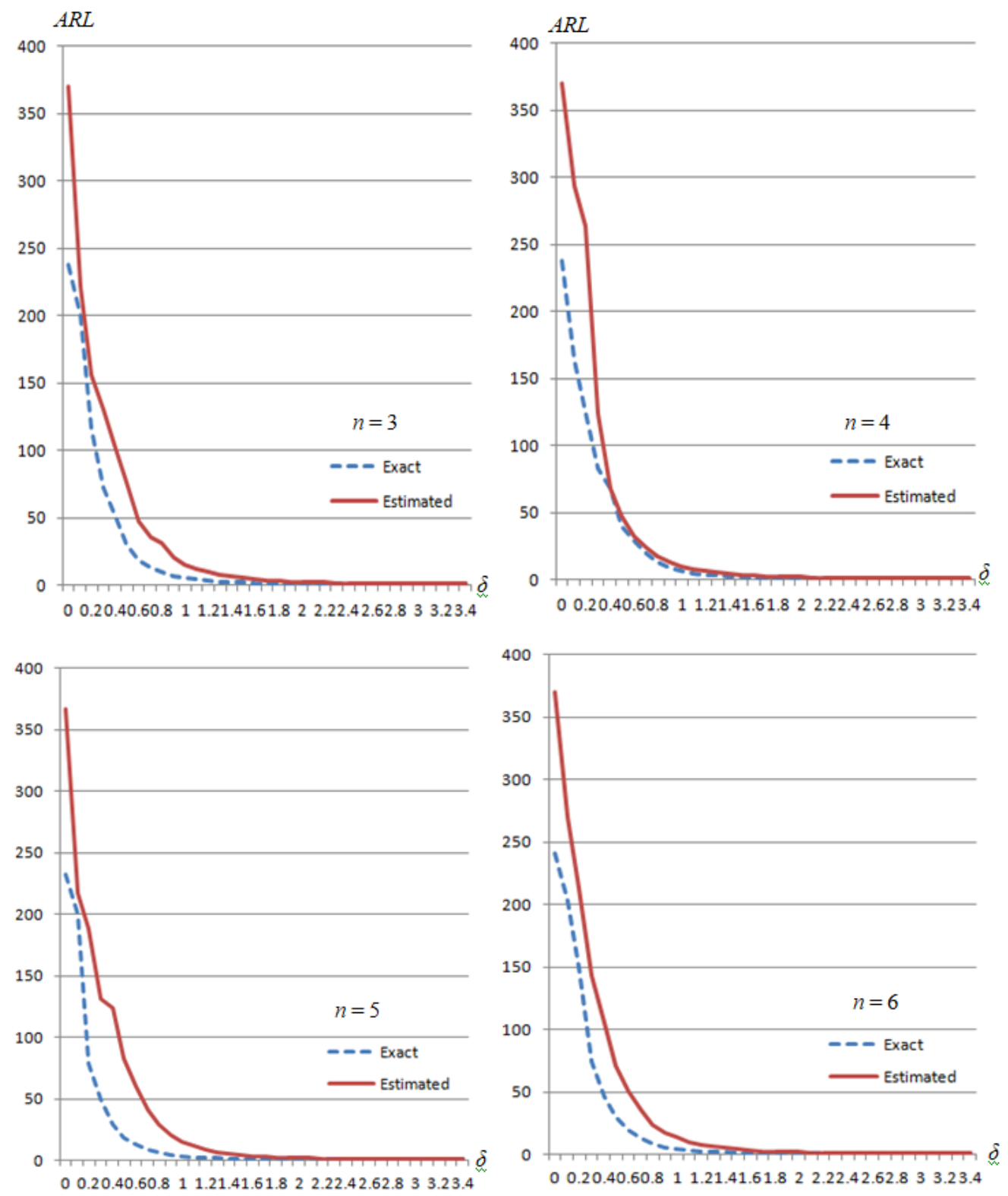

Figure 1 - Comparison between the ARL's when using the exact and estimated parameters of the Shewhart Control chart.

values ratio $=$ (inner coefficient/outer coefficient). For example, in table 3 this ratio equal to 0.69 for the Rep-RSS and it is 0.38 for Rep-ERSS. This means, by using Rep-RSS we expect that approximately $31 \%$ of the generated data will be re-sampled. However, it is $52 \%$ of the subgroup's will be re-sampled by using the Rep-ERSS scheme. Accordingly, it can be noted 
Table 3 - ARL using different methods when $n=3 ; \mathrm{r} 0=370$.

\begin{tabular}{|c|c|c|c|c|c|}
\hline Shift & SRS & RSS & ERSS & $\begin{array}{c}\text { Rep-RSS } \\
\mathrm{k} 1=3.03, \mathrm{k} 2=2.09\end{array}$ & $\begin{array}{c}\text { Rep-ERSS } \\
\mathrm{k} 1=3.18, \mathrm{k} 2=1.2\end{array}$ \\
\hline 0.0 & 369.68 & 340.56 & 340.4835 & 370.37 & 370.37 \\
\hline 0.1 & 351.27 & 321.85 & 319.1829 & 318.58 & 285.71 \\
\hline 0.2 & 305.25 & 254.77 & 247.5247 & 217.39 & 158.73 \\
\hline 0.3 & 254.71 & 185.19 & 184.2978 & 163.93 & 163.93 \\
\hline 0.4 & 202.47 & 128.51 & 133.7614 & 108.67 & 101.01 \\
\hline 0.5 & 153.23 & 128.50 & 91.2909 & 86.95 & 90.09 \\
\hline 1.0 & 43.31 & 18.89 & 18.87 & 14.99 & 12.09 \\
\hline 1.8 & 8.67 & 3.27 & 3.2947 & 2.96 & 2.74 \\
\hline 2.6 & 2.91 & 1.38 & 1.3774 & 1.24 & 1.36 \\
\hline 3.4 & 1.52 & 1.04 & 1.05 & 1.00 & 1.01 \\
\hline
\end{tabular}

Table 4 - ARL using different methods when $n=4 ; \mathrm{r} 0=370$.

\begin{tabular}{|c|c|c|c|c|c|}
\hline Shift & SRS & RSS & ERSS & $\begin{array}{c}\text { Rep-RSS } \\
\mathrm{k} 1=3.05, \mathrm{k} 2=2.12\end{array}$ & $\begin{array}{c}\text { Rep-ERSS } \\
\mathrm{k} 1=3.18, \mathrm{k} 2=1.224\end{array}$ \\
\hline 0.0 & 369.41 & 349.04 & 331.78 & 370.37 & 370.37 \\
\hline 0.1 & 341.71 & 312.30 & 304.59 & 303.03 & 185.19 \\
\hline 0.2 & 312.98 & 229.41 & 243.24 & 227.27 & 138.89 \\
\hline 0.3 & 256.01 & 166.75 & 179.69 & 117.64 & 121.95 \\
\hline 0.4 & 200.79 & 115.94 & 126.35 & 81.96 & 80.65 \\
\hline 0.5 & 156.12 & 76.70 & 88.12 & 62.11 & 46.30 \\
\hline 1.0 & 45.32 & 14.15 & 17.40 & 11.57 & 10.78 \\
\hline 1.8 & 8.88 & 2.48 & 3.01 & 2.24 & 2.38 \\
\hline 2.6 & 2.95 & 1.19 & 1.31 & 1.16 & 1.12 \\
\hline 3.4 & 1.52 & 1.01 & 1.03 & 1.01 & 1.01 \\
\hline
\end{tabular}

that by increasing the out of control-shifted value the $\mathrm{ARL}_{1}$ is decreases faster by using the Rep-ERSS than using Rep-RSS.

It could be noted that the ratio of the re-sampled subgroup's almost the same for the both repetitive schemes Rep-RSS, Rep-ERSS, and equal to $31 \%$ and 52\%, respectively. Even though, by transferring the control charts from in-control to our-of-control stage by a small shift (say 0.1 ), the ARL almost dropped down by $19 \%$ for Rep-RSS while it is almost $50 \%$ for the Rep-ERSS. Which means the Rep-ERSS is more sensitive to the out of control stage than the other sampling schemes. These results make the repetitive scheme is more robust than the classical schemes in the sense of un-acceptable samples or the percentage of the samples that exceed the control limits. Noting that, since we are using the 3 -sigma rule that makes almost $67 \%$ of the generated sub-samples using the traditional sampling schemes SRS, RSS and ERSS will be out of control. 
Table 5 - ARL using different methods when $n=5 ; \mathrm{r} 0=370$.

\begin{tabular}{|c|c|c|c|c|c|}
\hline Shift & SRS & RSS & ERSS & $\begin{array}{c}\text { Rep-RSS } \\
\mathrm{k} 1=3.06, \mathrm{k} 2=2.51\end{array}$ & $\begin{array}{c}\text { Rep-ERSS } \\
\mathrm{k} 1=3.21, \mathrm{k} 2=1.84\end{array}$ \\
\hline 0.0 & 369.41 & 356.76 & 350.7541 & 370.37 & 370.37 \\
\hline 0.1 & 341.71 & 301.93 & 298.8643 & 292.61 & 200.00 \\
\hline 0.2 & 312.98 & 225.83 & 229.8322 & 185.18 & 113.64 \\
\hline 0.3 & 256.01 & 152.46 & 164.4466 & 136.98 & 80.65 \\
\hline 0.4 & 200.79 & 98.42 & 107.1352 & 69.93 & 58.82 \\
\hline 0.5 & 156.12 & 65.33 & 74.0631 & 51.81 & 44.25 \\
\hline 1.0 & 45.32 & 11.05 & 13.5932 & 9.38 & 9.12 \\
\hline 1.8 & 8.88 & 2.01 & 2.3922 & 1.84 & 2.08 \\
\hline 2.6 & 2.95 & 1.10 & 1.1761 & 1.07 & 1.15 \\
\hline 3.4 & 1.52 & 1.00 & 1.01 & 1.00 & 1.01 \\
\hline
\end{tabular}

Table 6 - ARL using different methods when $n=6 ; \mathrm{r} 0=370$.

\begin{tabular}{|c|c|c|c|c|c|}
\hline Shift & SRS & RSS & ERSS & $\begin{array}{c}\text { Rep-RSS } \\
\text { K1=3.07, k2=2.73 }\end{array}$ & $\begin{array}{c}\text { Rep-ERSS } \\
\text { K1=3.2, k2=1.98 }\end{array}$ \\
\hline 0.0 & 370.52 & 346.14 & 331.12 & 370.37 & 370.37 \\
\hline 0.1 & 349.41 & 300.84 & 309.88 & 285.71 & 232.56 \\
\hline 0.2 & 309.02 & 218.77 & 232.66 & 212.55 & 169.49 \\
\hline 0.3 & 248.04 & 137.12 & 158.40 & 107.52 & 92.59 \\
\hline 0.4 & 198.89 & 87.00 & 110.60 & 62.50 & 64.52 \\
\hline 0.5 & 154.94 & 55.95 & 75.03 & 40.81 & 45.45 \\
\hline 1.0 & 45.57 & 9.00 & 13.66 & 7.73 & 9.57 \\
\hline 1.8 & 7.69 & 1.71 & 2.39 & 1.58 & 2.02 \\
\hline 2.6 & 2.93 & 1.05 & 1.17 & 1.04 & 1.12 \\
\hline 3.4 & 1.52 & 1.00 & 1.01 & 1.00 & 1.01 \\
\hline
\end{tabular}

The results in Table 5 indicated that using the repetitive sampling scheme will be much better than other novel sampling schemes (SRS, RSS or ERSS). In this Monte Carlo experiment, we set the in-control ARL is 370 which achieved around this value by using SRS or Rep-RSS or Rep-ERSS. Moreover, according to the inner and outer coefficients limits it could be noted that the percentage of un acceptable samples using Rep-RSS and Rep-ERSS are $18 \%$ and $47 \%$, respectively. in addition to, the ARL is decreases as the shifted value increases.

The results in Table 6 almost have the same inference as given in the previous tables. Moreover, in comparing the control charts based on different sampling schemes then the performance of the control chart measured with the a quick indication of whether the process is going out-of-control for small shifts. Accordingly, the proposed control chart is more efficient and performs better than all other control charts under the simulation plan assumptions for a small shift. For example, 
using the results in Table 6; when the set size is 6 and $\delta=0.3$, then the ARL1 $=248.04,137.12$, 158.4 and 107.52 using the SRS, RSS, ERSS and Rep-RSS schemes, respectively. While the ARL1 for the proposed control chart Rep-ERSS only requires 92.59 until detecting the process shift. Therefore, the proposed chart performs better with small shift. However, when the shift coefficient is increases ( 0.4 or more) only the Rep-RSS outperform the Rep-ERSS. Therefore, it is worth to recommend using the repetitive sampling with ranked data in the industry for monitoring the product standards using Shewhart control chart.

\section{CONCLUDING REMARKS}

In this article, we propose a new Shewhart control chart by using ranked repetitive sampling schemes. The performance of the proposed control charts investigated using the unconditional average run length's criterion. The results indicated that using repetitive sampling scheme increase the performance of the control chart. Accordingly, we recommend using repetitive sampling with ranked data to compute the Shewhart control charts. Moreover, in different Monte Carlo experiments, the control limits computed using different sampling schemes of the same size including SRS, RSS, ERSS, and repetitive ERSS. Then the performance of the Shewhart control charts are compared assuming different sample sizes and using unconditional ARL's criterion. The results showed that the use of ranked data and repetitive sampling helps in detecting the mean shifts in the process and that the proposed control chart outperforms the Novel control chart based on SRS, ERSS, or RSS. The use of the proposed control chart can be extended by using another sampling schemes based on robust ranked data such as RERSS or L RSS for a further study.

\section{ACKNOWLEDGEMENTS}

The authors are indebted to two anonymous referees for the suggestions, which significantly contributed to the improvement of this paper.

\section{References}

[1] Ahmad L, Aslam M, And Jun C-H. 2014. Designing of X-bar control charts based on process capability index using repetitive sampling. Transactions of the Institute of Measurement and Control, 36(3): 367-374.

[2] Al-Nasser AD \& Al-Omari AI. 2018. MiniMax Ranked Set Sampling. Revista Investigación Operacional. 39(4), 560-570.

[3] Al-Nasser AD \& Aslam M. 2019. Developing a New Control Chart based on Repetitive Ranked Set Sampling. In: Ranked Set Sampling: 65 years improving the accuracy in Data Gathering. Vol.1, pp: 9-23, Elsevier. 
[4] Al-Nasser AD \& Gogah FS. 2017. On using the median ranked set sampling for developing reliability test plans under generalized exponential distribution. Pakistan Journal of Statistics and Operation Research. 13(4), 757 -774.

[5] AL-NASSER AD 2007. L ranked set sampling: A generalization procedure for robust visual sampling. Communications in Statistics: Simulation and Computation, 36(1), 3343.

[6] Al-NASSER AD, \& Al-OMARI AI. 2015. Information theoretic weighted mean based on truncated ranked set sampling. Journal of Statistical Theory and Practice, 9(2), 313 329.

[7] Al-Nasser AD, \& Al-Rawwash M. 2007. A control chart based on ranked data. Journal of Applied Sciences (JAS), 7(14), 1936- 1941.

[8] Al-Nasser AD, \& Mustafa AB. 2009. Robust extreme ranked set sampling. Journal of Statistical Computation and Simulation, 79(7), 859-867.

[9] Al-Nasser AD, Al-Omari, AI, \& Al-Rawwash M. 2013. Monitoring the process mean based on quality control charts using on folded ranked set sampling. Pakistan Journal of Statistics and Operation Research, 9(1), 79-91.

[10] Al-Omari A, Al-Nasser AD \& Gogah F. 2016. Double acceptance sampling plan for time truncated life tests based on transmuted new Weibull-Pareto distribution. Electronic Journal Of Applied Statistical Analysis, 9(3), 520 - 529.

[11] AL-OMARI AI. 2015. Time truncated acceptance sampling plans for generalized inverted exponential distribution. Electronic Journal of Applied Statistical Analysis, 8(1): 1-12.

[12] Aslam M, Khan N, AZam M, \& Jun C-H. 2014. Designing of a new monitoring t-chart using repetitive sampling. Inf Sci. 269:210-216.

[13] Aslam M, Wang F, Khan N, \& Jun C-H. 2017. A multiple dependent state repetitive sampling plan for linear profiles. Journal of the Operational Research Society, , 1-8.

[14] BAKLizi A, El-Masri AQ, AL-NASSER AD. 2005. Acceptance sampling plans in the Rayleigh model . Communications for Statistical Applications and Methods.12(1): 11-18.

[15] BALAmurali, S. \& JUN C-H. 2006. Repetitive group sampling procedure for variables inspection. Journal of Applied Statistics, 33(3): 327-338.

[16] Chakraborti S. 2000. Run length, Average Run Length and false alarm rate of Shewhart X-bar: exact derivations by conditioning. Communications in Statistics Simulation and Computation, 29(1): 61-81.

[17] Claro Ae, Costa FB, \& Machado AG. 2008. Double sampling control CHART FOR A FIRST ORder AUTOREgRESSIVE PROCESS. Pesquisa Operacional, 28(3), 545-562. 
[18] Costa FB, \& MAchado AG. 2007. Synthetic control charts with two-stage sampling for monitoring bivariate processes. Pesquisa Operacional, 27(1), 117-130.

[19] Epprecht EK, Loureiro LD, \& Chakraborti S. 2015. Effect of the amount of Phase I data on the Phase II performance of $\mathrm{S}^{2}$ and S Control Charts. Journal of Quality Technology, 47(2):139-155.

[20] FREY J. 2016. A more efficient mean estimator for judgment post-stratification. Journal of Statistical Computation and Simulation, 86(7): 1404-1414.

[21] Gogah FS, \& AL-NASser AD. 2018. Median ranked acceptance sampling plans for exponential distribution. Afrika Matematika, 29(3-4): 477-497.

[22] Haq A, Brown J, Moltchanova E, \& Al-Omari AI. 2014. Mixed ranked set sampling design. Journal of Applied Statistics, 41(10), 2141-2156.

[23] Haq A, Brown J, Moltchanova E, \& Al-Omari AI. 2016. Paired double-ranked set sampling. Communications in Statistics - Theory and Methods, 45(10), 2873-2889.

[24] Haridy S, Ou Y, Wu Z, \& Khoo MBC. 2016. A single X chart outperforming the joint X \& R and X \& S charts for monitoring mean and variance. Quality Technology and Quantitative Management, 13(3), 289-308.

[25] He D, Grigoryan A, And Sigh M. 2002. Design of double-and triple-sampling X-bar control charts using genetic algorithms. International Journal of Production Research, 40(6): p. 1387-1404.

[26] Huang W-H, Yeh AB, Wang H. 2017. A control chart for the lognormal standard deviation. Quality Technology and Quantitative Management, 15(1): 1-36.

[27] JARDim FS, CHAKRABORTi S, \& EPPRECHT EK. 2019. Two perspectives for designing a phase II control chart with estimated parameters: The case of the Shewhart $\mathrm{X}^{-}$Chart. Journal of Quality Technology, 1-20.

[28] McIntyre GA. 1952. A method for unbiased selective sampling, using ranked sets. Australian Journal of Agricultural Research, 3: 385-390.

[29] Montgomery DC. 2009. Introduction to Statistical Quality Control. 6th ed, New York: John Wiley \& Sons, Inc.

[30] Nezhad M, and Saredorahi F. 2018. A new policy for designing acceptance sampling plan based on Bayesian inference in the presence of inspection errors. Communications in Statistics - Theory and Methods 47(21), 5307-5318. https://www.tandfonline. com/doi/abs/10.1080/03610926.2017.1390130

[31] OzTURK O. 2016. Estimation of a finite population mean and total using population ranks of sample units. Journal of Agricultural, Biological, and Environmental Statistics, 21(1), 181-202. 
[32] Rodrigues A, Epprecht EK, And Magalhães MSD. 2011. Double-sampling control charts for attributes. Journal of Applied Statistics, 38(1): 87-112.

[33] Saleh NA, Mahmoud MA, Keefe MJ, \& Woodall WH. 2015. The difficult in designing Shewhart and X control charts with estimated parameters. Journal of Quality Technology, 47(2): 127-138.

[34] Sherman RE. 1965. Design and evaluation of a repetitive group sampling plan. Technometrics, 7(1): 11-21.

[35] Shewhart WA. 1924. Some applications of statistical methods to the analysis of physical and engineering data, Bell Technical Journal, 3: 43-87.

[36] Shu L, HuAng W, AND Jiang W. 2014. A novel gradient approach for optimal design and sensitivity analysis of EWMA control charts. Naval Research Logistics (NRL), 61(3): 223-237.

[37] TAKAHASI K AND WAKImOTO K. 1968. On unbiased estimates of the population mean based on the sample stratified by means of ordering. Annals of institute of statistical mathematics, 20: 1-31.

[38] YAn A, LiU S, \& AzAm M. 2017. Designing a multiple state repetitive group sampling plan based on the coefficient of variation. Communications in Statistics: Simulation and Computation, 46(9): 7154-7165.

[39] Yaqub M, Abbas N, Riaz M, \& Shabbir J. 2016. On modified successive sampling based control charting schemes. Quality and Reliability Engineering International, 32(7), 2491-2497. doi:10.1002/qre.1951

[40] Zamanzade E \& Al-Omari AI. 2016. New ranked set sampling for estimating the population mean and variance. Hacettepe Journal of Mathematics and Statistics, 45(6): 1891-1905.

\section{How to cite}

Al-Nasser AD, Ciavolino E \& Al-OMari A. 2020. Extreme ranked repetitive sampling control charts. Pesquisa Operacional, 40: e226135. doi: 10.1590/0101-7438.2020.040.00226135. 